\title{
Cognição, Semiótica e Modelagem Articulações Possíveis
}

\author{
Zulma Elizabete de Freitas Madruga ${ }^{1}$ \\ Guy Barros Barcellos ${ }^{2}$ \\ José María Chamoso 3 \\ Valderez Marina do Rosário Lima ${ }^{4}$
}

\begin{abstract}
Resumen
Este artigo apresenta um ensaio teórico que aborda três teorias distintas: cognição, semiótica e modelagem, com o objetivo de articulá-las e, se possível, encontrar pontos convergentes que possam vir a auxiliar no processo de ensino e aprendizagem escolar. Como procedimento metodológico foi utilizado o Mapeamento na Pesquisa Educacional - Mapa Teórico, no qual foi realizada uma busca em obras que contivessem teorias consolidadas acerca da temática em estudo. Após análise destas teorias foi possível verificar que existem similaridades e pontos de compatibilidade, permitindo a tessitura de articulações que, se utilizadas por professores, podem facilitar o processo de aprendizagem dos estudantes por meio da modelagem.
\end{abstract}

Palavras-chave: Cognição. Semiótica. Modelagem na educação.

COGNITION, SEMIOTICS AND MODELING:

Possible Joints

\section{Abstract}

This article presents a theoretical essay addressing three distinct theories: cognition, semiotics and modeling, in order to articulate them and, if possible, find convergent points that assist in teaching and school learning process. As methodological procedure it was

1 Doutora em Educação em Ciências e Matemática. Universidade Estadual de Santa Cruz - Uesc. betefreitas.m@bol.com.br

2 Doutorando em Educação em Ciências e Matemática. Pontifícia Universidade Católica do Rio Grande do Sul PUCRS. guy@barcellos.pro.br

3 Doutor em Didática da Matemática. Universidad de Salamanca - Usal. jchamoso@usal.es

4 Doutora em Educação. Pontifícia Universidade Católica do Rio Grande do Sul - PUCRS. valderez. lima@pucrs.br 
used the Mapping in Educational Research - Map Theory, which was carried out on a farm works that contained consolidated theories about the subject under study. After analyzing these theories it can be seen that there are similarities and compatibility points, allowing the fabric joints that, if used by teachers, can facilitate the learning process of students through modeling.

Keywords: Cognition. Semiotics. Modeling in Education. 
A história da humanidade mostra variedades de produções - modelos. De acordo com Granger (1969), um modelo é uma imagem formada na mente quando uma pessoa busca compreender e expressar determinada percepção de fenômeno, seja este externo ou interno, e procura relacionar com algo conhecido. Já para Jacoby e Kowalik (1980), um modelo é uma aproximação de um protótipo, podendo ser objeto, sistema ou processo, utilizado por muitos profissionais, tais como artistas plásticos, arquitetos, engenheiros, escultores, desenhistas, economistas, administradores, cientistas, entre outros.

Durante a vida o cérebro cria modelos que são significativos para cada pessoa. Um modelo mental pode ser elaborado a partir de percepções advindas de experiências, visto que "quanto à experiência passada, pode aceitar-se que ela fornece uma informação direta e certa apenas dos objetos preciosos e do exato período de tempo, que se tornaram conhecimento seu [...]" (HUME, 1985, p. 38). Kenneth Craik (1914-1945) sugeriu, em 1943, que a mente poderia construir modelos de pequena escala, de situações imaginárias ou reais, e que eram utilizados para antecipar eventos. $\mathrm{O}$ ato de se fazer um modelo denomina-se "modelagem". Modelagem significa a ação de modelar, conjunto de processos e meio usados na confecção de modelos.

A noção de modelo e modelagem se faz presente em todas as áreas. Um modelo é um conjunto de símbolos criado de tal forma a representar alguma coisa. Essa representação pode se dar por meio de desenho ou imagem, projeto, esquema, gráfico, lei matemática, entre outras formas.

O presente artigo visa a relacionar modelos - modelagem, com outras teorias já consolidadas: "cognição e semiótica”, para apresentar convergências encontradas durante o estudo, e se for possível, a partir dos resultados, articular caminhos que possam ser utilizados na Educação Básica.

\section{Abordagem Metodológica}

Para tanto, optou-se por utilizar os procedimentos de Mapeamento na Pesquisa Educacional (BIEMBENGUT, 2008), mais especificamente no que diz respeito ao Mapa Teórico. De acordo com Biembengut (2008), a partir do 
Mapa Teórico é possível "ter uma visão do que existe sobre o tema", o qual será fonte para reconhecimento e análise de dados, propiciando certo domínio sobre o conhecimento produzido na área investigada.

Nesta pesquisa foi realizada uma busca teórica com relação a conceitos de cognição, semiótica e modelagem, teorias que por si sós já sustentam uma pesquisa. Cada uma delas foi estudada, e, posteriormente, procurou-se estabelecer pontos-chave e similaridades, articulando os dizeres dos autores na tentativa de encontrar caminhos que possam ser utilizados no ensino e aprendizagem de quaisquer áreas do conhecimento.

Para sustentar teoricamente a pesquisa foram destacados autores com sólidos conhecimentos nos três pilares desta pesquisa. Foram feitas ainda buscas em documentos como teses e artigos publicados em revistas qualificadas para verificar se há alguma pesquisa semelhante e que pudesse servir como base ou ponto de partida para este estudo. $\mathrm{O}$ intuito foi identificar se existem pesquisas que se relacionem de alguma maneira com a temática em questão. Em um primeiro momento não se encontrou nada que fosse possível classificar como semelhante, ou seja, articulando as teorias de Cognição, Semiótica e Modelagem.

A busca foi feita em duas partes: levantamento de teses e de artigos. A primeira etapa, em dois repositórios de teses: Banco de teses e dissertações da Capes $^{5}$ e Biblioteca Digital Brasileira de Teses e Dissertações - BDTD. Buscou-se teses que possuíam a palavra "Modelagem" no título e/ou palavras-chave.

No Portal Capes foram encontradas 54 teses, destas, 31 referiam-se a estudos das áreas de Engenharia, tais como: Química: 5; Mecânica 6; Elétrica: 5; Civil: 2; De Materiais: 2; Sanitária: 2; Agrícola: 2; Nuclear: 1; De Produção: 1; De Alimentos: 1; Tecnologia e Gestão (interdisciplinar): 4. As outras 23 teses referiam-se a áreas diversas: Geociências: 3; Química: 2; Geografia: 1; Agronomia: 1; Saúde Pública: 1; Bioquímica: 1; Biofísica: 1; Ciência da Computação: 1; Ciência da Informação: 1; Farmácia: 1; Zootecnia: 1; Ecologia: 1; Educação: 2 e Ensino de Ciências e Matemática: 6. Desta busca retirou-se então as teses

${ }^{5}$ Coordenação de Aperfeiçoamento de Pessoal de Nível Superior. 
que se referiam à Educação e ao Ensino de Ciências e Matemática, resultando em 8 analisadas. Cabe destacar que o Portal Capes possui em seu banco teses e dissertações publicadas a partir de 2010.

Na Biblioteca Digital de Teses e Dissertações também com buscas pela palavra "modelagem" nos mesmos moldes da anterior, foram encontradas outras 34 teses divididas da seguinte forma: Engenharias: 16; Gestão: 2; Geociências: 4; Química: 4; Música: 1; Computação: 2; Física: 2 e Matemática Aplicada: 3. Como a procura era por teses que apresentassem relação com ensino e/ou educação, as teses de Química, Física e Matemática Aplicada foram excluídas deste estudo por se tratarem de conhecimentos técnicos referentes a cada disciplina. Salienta-se que as teses buscadas neste repositório foram a partir do ano de 2005, pois a intenção era procurar por pesquisas recentes que refletissem o panorama atual da área, neste caso, buscaram-se por teses publicadas nos últimos 10 anos.

A busca realizada em periódicos seguiu os seguintes critérios: 1) Foram selecionadas Revistas A1 e A2 do Qualis Capes “ensino" que tivessem em seu escopo artigos de Ciências e Matemática, principalmente, e em um segundo momento de Revistas de Educação de uma maneira geral, excluindo todas as específicas de alguma disciplina que não fosse a Matemática. Neste critério foram analisadas as seguintes Revistas A1: Bolema; Ciência \& Educação, Enseñanza de las Ciencias, La Matematica y la sus didácticas, Revista de Educación de las Ciencias, Revista Eletronica de Investigación Educativa e Revista Lusófona de Educação; e ainda as qualificadas como A2: Revista de Investigación (Caracas), Revista Eletronica de Investigación en Educación en Ciencias (En Línea), Revista Mexicana de Investigación Educativa, Revista Brasileira de Pesquisa em Educação em Ciências, Revista Brasileira de Educação, Revista Eletrônica de Enseñanza de las Ciencias (REEC), Paradigma (Maracay), Investigações em Ensino de Ciências, Interface, Educação em Revista, Educar em Revista e Ensaio: Pesquisa em Educação em Ciências.

Em todas estas publicações anteriormente mencionadas, as buscas foram feitas entre os anos de 2005 e 2015, por artigos que contivessem a palavra "modelagem" no título e/ou palavras-chave. Desta busca foram excluídos artigos 
que tratassem de Matemática Aplicada ou outro ramo específico, considerando apenas as que tivessem relação com educação e/ou ensino, ou seja, a busca foi por modelagem na educação.

Foram encontrados 48 artigos de modelagem, no entanto apenas um tem alguma relação com a temática deste estudo, mas com outro foco. Após análise do resumo e leitura flutuante de cada um dos artigos, pôde-se categorizá-los da seguinte forma: Matemática e seus discursos (2); Aspectos epistemológicos da Modelagem (1); Perspectivas sociocríticas da Modelagem (4); Modelagem e diferentes tendências da Educação Matemática (1); Significados da pesquisa qualitativa em Modelagem (1); Obstáculos e resistências em Modelagem (2); Concepções de Modelagem (1); Percepções e formação de professores (8); Atividades de Modelagem (16); Modelagem e Tecnologias (5); Modelagem em disciplinas de Ciências (5); Modelagem e semiótica (1) e Modelagem, semiótica e cognição (1).

Dos artigos analisados, dois despertaram especial interesse para este estudo, pois tratam de teorias utilizadas como base neste artigo: Modelagem e semiótica e Modelagem, semiótica e cognição. Estes dois artigos foram analisados cuidadosamente, porém percebeu-se que o seu foco não converge com os objetivos desta pesquisa.

No primeiro artigo destacado, que trata de "modelagem e semiótica", Almeida, Silva e Vertuan (2011) buscam uma aproximação entre a semiótica peirciana, em particular as categorizações fenomenológicas e os níveis de relações dos signos estabelecidos por Peirce e a Modelagem Matemática na concepção de alternativa pedagógica. Para tanto foi analisada pelos autores uma atividade de modelagem que lhes permitiu perceber que existem relações que são "primeiras", ações que são "segundas" e ações que são "terceiras" durante o desenvolvimento de uma atividade de Modelagem Matemática, estabelecendo assim uma sintonia com as categorias primeiridade, secundidade e terceiridade de Peirce.

Durante a análise dos níveis de relações (significação, objetivação e interpretação), Almeida, Silva e Vertuan (2011) buscaram verificar a efetivação destes níveis pelos alunos. Para isso, foram feitas observações acerca das relações 
ou generalizações conceituais emitidas por estes alunos durante suas ações, o que, segundo os autores, possibilitou a observação de elementos indicativos do pensar refletidos nas representações apresentadas para a atividade estudada.

Este artigo apresentou uma teoria densa sobre a semiótica de Peirce e analisou uma atividade de Modelagem Matemática desenvolvida por um grupo de alunos do $1^{\circ}$ ano de Licenciatura em Matemática no âmbito de um curso de Modelagem Matemática extracurricular no início do $1^{\circ}$ semestre letivo desta série. Segundo Almeida, Silva e Vertuan (2011), a primeiridade aparece no momento em que os alunos têm o primeiro contato com a atividade desenvolvida, a secundidade relaciona-se à busca de informações e a terceiridade está relacionada com as etapas de obtenção e dedução do modelo matemático, ou seja, na obtenção dos resultados e sua validação. Segundo os autores, para Peirce a função representativa do signo baseia-se em uma relação deste com um pensamento. Esta afirmação parece estar em sintonia com procedimentos desenvolvidos pela Modelagem. Assim, a aproximação buscada no artigo analisado ancorou-se na importância de um contínuo representar na construção de generalizações durante o processo de modelar.

No artigo que trata das teorias bases deste estudo: "modelagem, semiótica e cognição”, Almeida e Silva (2012) apresentam algumas reflexões, à luz da semiótica peirciana, sobre a possibilidade de se introduzir em sala de aula atividades que apontem para um potencial desenvolvimentos de diferentes tipos de raciocínio, bem como de diferentes ações cognitivas nos estudantes. Os autores iniciam com um referencial teórico acerca de semiótica, especificamente no que diz respeito aos modos de inferência, abdução, dedução e indução e também acerca de Modelagem Matemática na concepção de alternativa pedagógica. Almeida e Silva (2012) tinham como objetivo investigar as relações entre as ações cognitivas evidenciadas em atividades de modelagem e seus modos de inferência.

Para isso as autoras analisaram uma atividade de modelagem desenvolvida por alunos de um curso de Licenciatura em Matemática, e, a partir da análise, concluíram que os modos de inferências ativados na atividade analisada estão associados às ações cognitivas dos estudantes durante as transições entre as diferentes etapas do desenvolvimento da atividade de modelagem. Almeida e Silva 
(2012) afirmam que quando os estudantes se utilizam de conceitos matemáticos que partem de situações-problema da realidade, e desenvolvem representação matemática destas situações por meio de atividades investigativas, é requerida a utilização de diversos tipos de raciocínio, que proporcionam diferentes ações cognitivas. Dessa forma, Almeida e Silva (2012) defendem que a Modelagem Matemática constitui uma alternativa pedagógica que pode proporcionar importantes ações cognitivas, requerendo diferentes modos de inferência.

Das buscas e análises de teses e artigos, constatou-se que não há nenhuma pesquisa publicada entre os anos de 2005 e 2015 que trate de modelagem na concepção de método de pesquisa aplicado à educação e suas relações com semiótica e cognição, objetivando articulá-las na busca por pontos convergentes que possam auxiliar no processo de ensino e aprendizagem escolar.

A seguir são explicitadas as teorias que lastreiam o viés analítico desta pesquisa para posteriores articulações e elucidações concernentes ao fulcro criativo e investigativo deste texto.

\section{a) Cognição}

Ato de conhecer ou adquirir conhecimento, ou ainda a função da inteligência ao adquirir tal conhecimento, são as definições dicionarizadas. Para Blakemore e Frith (2007), cognição é tudo aquilo que tenha referência com a esfera mental, a qual engloba pensamento, memória, atenção, aprendizagem, ações mentais e emoções. Nesse sentido, diversos processos cognitivos são requeridos para a elaboração do conhecimento que poderão conformar comportamentos. Tais processos são complexos, pois implicam um conjunto de estruturas as quais percebem, filtram, organizam, modelam, compreendem, significam e expressam informações e dados provenientes do meio, amalgamando-os em impressões, ideias e pensamentos.

A partir do meio em que se insere a pessoa capta sensações e percepções a todo instante, as quais geram na mente ideias, imaginações e modelos. Quando se compreende e se entende tais percepções, algumas delas transformam-se em significado, em modelos elaborados, portanto, em conhecimento. A todo 
momento as pessoas recebem informações pelos órgãos dos sentidos, logo, é necessário que a mente selecione aquelas significativas de fato para, então, compreender e transformar em conhecimento.

Dessa forma, faz-se um apanhando da teoria de neurocientistas acerca de “como o cérebro aprende”, ou seja, como este conhecimento é gerado. Variados autores serão consultados, mas as ideias de Leonor Guerra (2013, 2015) serão a base da reflexão apresentada. Assim, nas páginas que seguem, são discutidos os entendimentos e definições de neurocientistas, em diálogos sobre neurociência e educação.

De um ponto de vista neurobiológico, aprendizagem é a aquisição de novos comportamentos, e estes dependem da atividade do sistema nervoso. A pessoa aprende, ou seja, adquire novos comportamentos, em todos os ambientes em que atua e interage. Segundo Johnson-Laird (1990), a aprendizagem consiste em transformações relativamente permanentes que ocorrem como resultado da experiência, ou seja, quando uma pessoa é capaz de fazer algo que não podia fazer antes, ou torna-se capaz de fazê-lo melhor. Ademais, os comportamentos das pessoas podem ser governados por suas recordações e experiências passadas, as quais são armazenadas em forma de conhecimento (Johnson-Laird, 1990).

Na intelecção de Guerra (2013, 2015), o sistema nervoso desenvolveu-se ao longo da evolução biológica para aquisição de comportamentos que garantissem a sobrevivência e o bem-estar dos seres vivos que o possuem, com o intuito de garantir a preservação dos genes. ${ }^{6}$ Assim, pode-se afirmar que a aprendizagem é para a vida. Esta reflexão é importante no que se refere ao âmbito da sala de aula, ou seja, o sistema nervoso do estudante produz as aprendizagens, na medida em que aquela aprendizagem for relevante e significativa para a vida dele, afirma Guerra (2013). O sistema nervoso é o início e o fim de qualquer processo cognitivo. É o ponto de convergência e divergência de tudo o que pensa e faz qualquer ser humano. Não há cognição sem sistema

6 Tal concepção é defendida pelo etólogo e biólogo evolucionário Richard Dawkins (1942-), professor emérito de Oxford, quando afirma serem os genes e não as espécies as "unidades" de seleção natural, o que propele a evolução biológica de todos os seres vivos (DAWKINS, 2007). 
nervoso, este é condição sine qua non para existir conhecimento. Reconhecer seu funcionamento, portanto, é essencial para (re)pensar quaisquer articulações teóricas em práticas no universo da educação.

Assim, cabe destacar que o estudante aprende interagindo com o ambiente. Isso implica que a dimensão social da cultura e da comunidade em que se insere, ou seja, tudo que envolve o conjunto de estímulos captados pelas vias sensoriais, servem como fatores que irão levá-lo a elaborar aprendizagens. O cérebro $^{7}$ humano dedica-se àquilo que causa prazer ou exatamente o oposto, sempre implicando primariamente em sua sobrevivência e, também, seu bem-estar psicobiológico. O tipo de emoção, bem como sua intensidade, extensão e consequências são fatores da qualidade de aprendizagem que se elabora, bem como determinantes na sua "durabilidade".

De uma perspectiva estritamente biológica, o sistema nervoso dos vertebrados é constituído de várias células nervosas - os neurônios. São células “estreladas", dotadas de um corpo celular com ramificações - os dendritos, ${ }^{8} \mathrm{e}$ um prolongamento revestido de mielina, pelo qual passam impulsos elétricos -o axônio. A função dos neurônios é receber e enviar as informações pelos dendritos, entre eles, e passar para outras células por meio do axônio. Os pontos de comunicação entre neurônios são chamados de sinapses, entre essas conexões ocorrem trocas de neurotransmissores e descargas elétricas, que modulam ações bioquímicas e fisiológicas.

De acordo com Johnson-Laird (1990), o cérebro contém células nervosas que produzem impulsos, os quais consistem em trocas eletroquímicas que se propagam em diversas intensidades, e por meio destas fibras nervosas é selada a união (sinapse) entre um nervo e outro, mediante outros processos elétricos e químicos.

7 O cérebro aparece aqui como representante do sistema nervoso (encéfalo, medula espinal e nervos).

8 Termo que deriva do vocábulo grego $\delta \varepsilon ́ v \delta \rho o v($ dendron), que significa "árvore". Chama-se assim esta estrutura devido ao fato de suas ramificações assemelharem-se a galhos. 
Quando um neurônio é ativado, ou seja, quando ocorre uma modificação eletroquímica, ele também sintetiza neurotransmissores, responsáveis por estimulações e inibições de diversas funções do organismo, de natureza endócrina, absortiva, excretora ou integradora. Um neurônio ativado pode também ativar outros clusters de substância cinzenta, dedicados a variadas funções cerebrais. O imenso número de neurônios de um ser humano entre 30 e 50 anos (86 bilhões) pode multiplicar a números na casa dos trilhões as suas ramificações e a incalculáveis sinapses. Novos aprendizados implicam novas conexões, não necessariamente significando um aumento da população de neurônios de uma pessoa.

Nas sinapses há vesículas com neurotransmissores, os quais são macromoléculas liberadas na fenda sináptica quando um neurônio pré-sináptico está ativado. Essas moléculas encontram receptores de membrana no neurônio pós-sináptico, promovendo alterações eletroquímicas e subsequentes modulações fisiológicas. Posteriormente, os neurotransmissores retornam para serem reaproveitados.

Existem neurônios, nos órgãos dos sentidos, que têm como função traduzir percepções visuais, sonoras, olfativas e tácteis do ambiente. Esses neurônios possuem prolongamentos - axônios que podem, em feixes, formar nervos - que chegam até esses órgãos dos sentidos, cujo corpo celular localiza-se na medula espinal. No corpo desse neurônio existe um axônio que vai comunicar com outro neurônio dentro do encéfalo. Dessa forma, cada estímulo recebido pelos órgãos dos sentidos gera alterações eletroquímicas naquela célula nervosa que está recebendo tal estímulo (célula aferente). Ou seja, na medida em que há interação, o que a pessoa produz é consequência do que o cérebro percebe, processa, interpreta - integrando ao que já possui em seu acervo - e responde, tudo isso a partir dessas interações (GUERRA, 2013).

Por meio das percepções e interações podem ocorrer aprendizagens, processo de variados, porém sempre altos, níveis de complexidade para um sistema biológico. Em se tratando de primatas, incluindo-se o Homo sapiens, tal complexidade pode gerar o fenômeno da cultura. Guerra $(2013,2015)$ afirma que o educador em seu cotidiano está criando ensejos para modificações 
de conexões, sinapses, estrutura cerebral dos estudantes (e de si) por meio dos órgãos dos sentidos, ou seja, da interação. Nestes casos a interação está levando a modificações eletroquímicas no sistema nervoso e resulta em novas confirmações da árvore dendrítica no cérebro da pessoa por um processo chamado neuroplasticidade.

Blakemore e Frith (2007) entendem por plasticidade a capacidade do sistema nervoso de se adaptar continuamente a diferentes circunstâncias. De acordo com os autores, alguns estudos sobre plasticidade sugerem que o cérebro está estruturado para aprender durante toda a vida e adaptar-se ao meio, mesmo na idade adulta. Vale ressaltar que, para Guerra (2013), neuroplasticidade é a propriedade de "fazer e desfazer" conexões entre os neurônios, possibilitando uma reorganização da estrutura do sistema nervoso e do cérebro, constituindo-se como base biológica da aprendizagem, bem como do esquecimento, esse fenômeno imanente implicado no processo cognitivo. Em suma, é a neuroplasticidade que permite ao sistema nervoso se reorganizar e expressar novos comportamentos adquiridos. Assim, a aprendizagem pode ser considerada um processo de reorganização cerebral cotidiano.

Guerra (2013) também afirma que as proteínas não formam ou modificam os arranjos dendríticos enquanto o sistema nervoso está interagindo e recebendo as informações. Enquanto ocorre a interação, o que processa a informação é a "memória de curta duração" ou "memória de trabalho", também chamada de "memória operacional". Para Blakemore e Frith (2007), memória de curta duração é um sistema que permite à pessoa guardar e manipular informações, constituindo uma pequena região do córtex pré-frontal que desempenha o papel de armazenamento de informações e recordações durante curto prazo. A memória de curta duração não está consolidada fisicamente no cérebro, diferentemente da memória de longa duração. Essa memória significa a informação passando pelos neurônios, mas sem fazer uma modificação física - rearranjos físicos nessa rede neural.

A aprendizagem, ou memória de longa duração, não ocorre somente durante o período de vigília da pessoa. É durante o sono que as informações, ou parte delas, ficam "rodando" no cérebro, produzindo assim algumas sinap- 
ses dendríticas. Isso não significa, entretanto, que a pessoa tenha memorizado a informação recebida de maneira ampla e profunda. Para que isso ocorra é necessário que a informação esteja vinculada a emoções intensas (positivas ou não) ou que a pessoa revisite a informação repetitivamente, buscando estudá-la ${ }^{9}$ (por exemplo: passos de dança, hinos, discursos, elementos da tabela periódica) ou por repetição espontânea (por exemplo: caminho de casa, senhas pessoais, nomes de alunos e colegas). É necessário, no entanto, o período de sono para consolidação da memória. É também durante o sono que há formação da memória de longa duração, ou seja, é nesse período que o cérebro consolida e organiza as memórias recebidas ao longo do dia, afirma Guerra (2013).

Este processo não é feito de uma vez só, por este motivo acredita-se que a aprendizagem ocorre de forma "espiralada", o que se sabe é (re)apre(e) ndido ao longo de vivências que evoquem o que se aprendeu ou que recapitulem algum aprendizado, não necessariamente de forma idêntica à primeira. Não é na primeira vez que se aprende alguma coisa, pois também se aprende a partir do que já se sabe, acoplam-se aprendizados. Aprendizados constroem um arcabouço que servirá de substrato para a elaboração de novos aprendizados, mais complexos e que se complexificam ao serem entrelaçados ao que já se havia consolidado. Muito se percebe durante um dia, milhares são os estímulos recebidos (percepções), mas pouco se compreende, e muito menos ainda se significa, ou seja, modifica o cérebro da pessoa gerando assim aprendizagem, transformando-se em conhecimento.

Assim, o conhecimento (humano) do mundo é adquirido (existe) devido ao sistema nervoso, e a partir destes conhecimentos pode-se efetuar uma representação deste mundo. É por meio da percepção que as pessoas tomam conhecimento do mundo. George considera que na primeira fase do processo cognitivo acontece uma "produção divergente (ou indução), cognição e valoração [...]. A segunda consiste em dividir em termos dos produtos do pensamento,

\footnotetext{
9 Aqui não se busca entrar no mérito da complexidade multiscópica do aprendizado, visa-se somente a explicar - de maneira sucinta - o mecanismo per se, na sua funcionalidade. Naturalmente, no aprendizado ocorre trâmite processos de sofisticação em cujos pormenores não se busca entrar, visto a natureza deste estudo lançar mão destas explicações para que enriqueçam a análise. Ou seja, não constitui o fulcro da pesquisa discutir psicologicamente o aprendizado.
} 
por exemplo: unidades, classes, relações, etc. E finalmente, a terceira forma refere-se aos tipos de conteúdos, tais como figurativo, simbólico e semântico" (1973, p. 18).

Nessa perspectiva, cabe ressaltar que Kant ${ }^{10}$ denominou três ações da faculdade do conhecimento envolvidas no processo cognitivo como:

- Apreensão do diverso na imaginação;

A imaginação é a faculdade que enlaça os elementos diversos da intuição sensível, que depende do entendimento pela unidade de sua síntese intelectual, e da sensibilidade pela diversidade da apreensão. Mas como toda percepção possível depende da síntese da apreensão, e esta síntese empírica da síntese transcendental, e por conseguinte, das categorias, todas as percepções são possíveis (KANT, 1980, p. 66).

- Compreensão deste diverso na consciência, em um conceito de objeto, por meio do entendimento; "e também tudo o que pode chegar à consciência empírica, quer dizer, todos os fenômenos da natureza se acham, quanto a sua união, sujeitos às categorias das quais depende a natureza [...] como da razão primitiva de sua legitimidade necessária" (KANT, 1980, p. 67).

- Exposição do conceito deste objeto na intuição, mediante a faculdade de juízo.

Mas a faculdade do entendimento puro não pode prescrever "a priori" outras leis aos fenômenos por simples categorias que servem de fundamento a uma natureza em geral, como legitimidade dos fenômenos em tempo e espaço. Referindo-se empiricamente a fenômenos determinados, não podem as leis particulares proceder somente das categorias do entendimento, não obstante todas se acharem submetidas a estas (KANT, 1980, p. 67).

As três "fases" do processo de conhecimento criadas por Kant servirão de subsídios a outros autores que serão trazidos ao longo deste estudo.

${ }^{10}$ Immanuel Kant (1724-1804) viveu e morreu em Königsberg, uma cidade da Prússia Oriental (Alemanha) e foi considerado um dos maiores filósofos da História. A obra de Kant (1980), referenciada neste artigo é uma tradução de "Crítica do Juízo" - publicada pela primeira vez em 1790. Nesta, o autor apresenta e discute o conceito de juízo estético (KANT, Immanuel. Primeira Introdução à Crítica do Juízo. Trad. Torres Filho, R. R. São Paulo: Abril Cultural, 1980). 


\section{b) Semiótica}

Semiótica, para Santaella (2003), é a ciência geral de toda e qualquer linguagem, é a "ciência dos signos". Semiótica é a doutrina filosófica geral dos sinais e símbolos, especialmente das suas funções, é a ciência dos modos de produção, de funcionamento e de recepção dos diferentes sistemas de sinais e de comunicação entre as pessoas. A semiótica emergiu em consequência dos estudos de Ferdinand de Saussure ${ }^{11}$ e Charles Sanders Peirce. ${ }^{12}$ A palavra semiótica origina-se do grego semeion, que significa "signo". Semiótica é a ciência geral dos signos. Tem a função de analisar a relação do signo com a linguagem.

Ferdinand de Saussure (1857-1913), um dos fundadores da semiótica, afirmava ser a língua um sistema de signos que exprimem ideias e, por isso, confrontável com a escrita, com o alfabeto dos surdos, com os ritos simbólicos, com as fórmulas de cortesia, com os sinais militares, entre outros. Os signos, para ele, são instrumentos de comunição e representação dos objetos e da realidade.

Peirce (1839-1914) definiu semiótica como a doutrina da natureza essencial e das variedades fundamentais de cada semiose possível. Peirce entendia semiose como uma ação, uma influência que envolve a cooperação de três coisas: um signo, seu objeto e seu interpretante. Para Peirce, signo é qualquer coisa que está para alguém no lugar de algo, sob determinados aspectos ou capacidades. Neste estudo serão desenvolvidas as ideias de Peirce.

Peirce afirmava que a linguagem se dá por intermédiode signos, e por meio deles é que se tem acesso à realidade.

A noção de signo da semiótica peirciana é muito genérica e abrangente. Para se ter uma idéia dessa abrangência, é necessário levar em conta que Peirce incluiu sob o termo signo "qualquer pintura, diagrama, grito natural, dedo

${ }^{11}$ Ferdinand de Saussure (1857-1913), linguista e filósofo suíço cujas elaborações teóricas propiciaram o desenvolvimento da Linguística.

${ }^{12}$ Charles Sanders Peirce (1839-1914), filósofo, cientista e matemático americano, cujos trabalhos apresentaram grandes contribuições à lógica, matemática, filosofia, e, sobretudo, à semiótica. 
apontando, piscadela, mancha em nosso lenço, memória, sonho, imaginação, conceito, indicação, ocorrência, sintoma, letra, numeral, palavra, sentença, capítulo, livro, biblioteca", etc. (SANTAELLA, 2009, p. 39).

Para Peirce (2012), ${ }^{13}$ signo ou representamem, é aquilo que sob certo aspecto ou modo representa alguma coisa para alguém. E este cria na mente um signo equivalente ou mais desenvolvido. Signo é qualquer coisa de qualquer espécie, podendo estar no universo físico ou no mundo do pensamento. Segundo o autor, um signo pode representar o objeto ou referir-se a ele. O signo criado Peirce $(1975)^{14}$ chama de interpretante do primeiro signo.

O signo representa alguma coisa, seu objeto. O signo (ou representamen) é resultante de três elementos: o fundamento, o objeto e o interpretante. Conforme Peirce (2012), para que algo seja considerado um signo deve representar algo que é chamado objeto. Os signos são divididos de acordo com as seguintes tricotomias: a primeira é a relação do signo consigo mesmo, dependência do signo ser em si mesmo, mera qualidade, concreto; a segunda é a relação do signo com seu objeto, ou seja, consiste em o signo ter algum caráter por si mesmo ou estar em alguma relação existencial para com aquele objeto ou em sua relação para com um interpretante; a terceira tricotomia consiste na relação do signo com seu interpretante, "na dependência de seu interpretante representá-lo como signo de possibilidade, ou com um signo de fato, ou com um signo de razão" (PEIRCE, 2012, p. 51).

Santaella (2003) explica as três categorias definidas por Peirce. Essas categorias podem ser chamadas de modalidades possíveis de apreensão de todo e qualquer fenômeno: primeiridade, secundidade e terceiridade.

\footnotetext{
${ }^{13}$ A obra que se refere a Peirce (2012) trata-se de uma tradução e reedição da obra: PEIRCE, Charles S. Semiótica. São Paulo: Perspectiva, 2012.

${ }^{14}$ A obra que se refere a Peirce (1975) trata-se de uma tradução e reedição da obra: PEIRCE, Charles S. Semiótica e filosofia. São Paulo: Cultrix, 1975.
} 


\section{- Primeiridade}

Tudo que está imediatamente presente à consciência de alguém, é tudo aquilo que está na mente no instante presente (SANTAELLA, 2003). Primeiridade significa qualidade, possibilidade. É o iniciante, original, espontâneo e livre. Precede toda síntese e toda diferenciação; não tem unidades nem partes. Qualquer coisa que esteja na mente a qualquer momento, há necessariamente uma consciência imediata e consequentemente um sentimento. "Consciência em primeiridade é qualidade de sentimento e, por isso mesmo, é a primeira, ou seja, a primeira apreensão das coisas que para nós aparecem, [...] película de mediação entre nós e os fenômenos" (p. 10).

\section{- Secundidade}

Tem relação com existência, mundo real, reativo, independente do pensamento e, no entanto, pensável, que se caracteriza pela secundidade. "Esta é a categoria que a aspereza e o revirar da vida tornam mais familiarmente proeminentes. É a arena da existência cotidiana" (SANTAELLA, 2003, p. 10). Agir, reagir, interagir e fazer são modos marcantes, concretos e materiais de dizer o mundo, interação dialógica, ao nível da ação, do homem com sua história. Secundidade, de acordo com Santaella (2003), é aquilo que proporciona à experiência seu caráter factual, de luta e confronto. Ação e reação em nível de binaridade, sem regência da camada mediadora da intencionalidade, reação ou lei.

\section{- Terceiridade}

Tem relação com "lei". Aproxima um primeiro e um segundo em uma síntese intelectual, correspondente à camada de inteligibilidade, ou pensamento em signos por meio da qual uma pessoa representa e interpreta o mundo. Segundo Santaella (2003), terceiridade tem relação com generalidade, infinitude, continuidade, difusão, crescimento e inteligência, no entanto a mais simples ideia de terceiridade é aquela de um signo ou representação.

Na segunda tricotomia - relação do signo com seu objeto - Peirce (2012) afirma que um signo pode ter três denominações: ícone, índice (indicador) e símbolo, a saber: 
Um ícone é um signo que se refere ao objeto que denota simplesmente por força de caracteres próprios que ele possui. Qualquer coisa, seja uma qualidade, um existente individual ou uma lei, será um ícone de algo, na medida em que é semelhante a esse algo usado como signo dele.

É um signo cuja qualidade representativa é uma primeiridade, isto é, uma qualidade que ele possui para torná-lo apto a ser um signo. Assim, qualquer coisa tem condição de ser um substituto para outro que se assemelhe. Um ícone é uma imagem do seu objeto e, em termos mais estritos, só pode ser uma ideia, pois deve produzir uma ideia interpretante, e um objeto externo excita uma ideia por meio de uma reação sobre o cérebro. Ícone é um signo que se refere ao objeto que denota, por força de caracteres próprios. Será um ícone de algo, na medida em que é semelhante, ou similar a esse algo, e usado como signo dele.

Segundo Peirce (1975, p. 117), "o único meio de transmitir diretamente uma ideia é por via de um ícone, e todo método indireto de comunicar uma ideia deve depender, para seu estabelecimento, do uso de um ícone”. Exemplos de ícones podem ser: pintura, fotografia, escultura, diagrama, equações algébricas, entre outros. Uma equação algébrica é considerada um ícone pelo fato de fazer com que se assemelhem quantidades que mantêm relação análoga com o problema.

Uma característica do ícone é o fato de ele ser possuidor de caráter que o torna significativo, ainda que o objeto não exista mais. Por exemplo, se uma foto for tirada de um desfile de escola de samba, mais precisamente de um carro alegórico, no ano seguinte o ícone - foto- ainda existirá, mas o objeto (carro alegórico) não existirá mais. Pode-se afirmar que o carro não mais existirá, pois é prática das escolas de samba de um modo geral desmanchar as alegorias para a construção das novas. $O$ fato de o objeto não existir não invalida a foto (signo) - ícone.

Um indicador, ou índice, é um signo que se refere ao objeto que denota, em razão de se ver realmente afetado por aquele objeto. $\mathrm{O}$ índice funciona para indicar outra coisa com a qual está ligado. É um ponto que irradia para várias 
direções, funciona como signo quando a mente interpretadora estabelece a conexão em uma dessas direções. Um índice é sempre dual: ligação de uma coisa com outra.

Exemplos de índice podem ser: pegadas na areia, pancada na porta, nuvens escuras, relâmpago, fumaça, entre outros. Qualquer coisa que atraia a atenção, ou que de alguma forma surpreenda, pode ser considerada exemplo de índice. Um índice é um signo que perderia seu caráter que o faz signo caso o objeto fosse eliminado, por exemplo, se há fumaça, há fogo. Se cessar o fogo, a fumaça (índice) deixará de existir.

Um símbolo é um signo que se refere ao objeto que denota por força de uma lei, geralmente uma associação de ideias gerais que operam no sentido de levar o símbolo a ser interpretado como se referindo àquele objeto. É um signo cujo caráter representativo consiste em ser uma regra que determinará seu interpretante. Segundo Peirce (1975), todas as palavras, sentenças, livros e outros signos convencionais são símbolos. Símbolo é um sinal convencional que provém de um acordo e combinação social.

São exemplos de símbolos: um estandarte, uma insígnia, uma senha, um emblema, um credo religioso, qualquer bilhete, documento, expressão de sentimento ou palavra comum. O símbolo também é aplicável a tudo aquilo que possa concretizar a ideia relacionada com a palavra.

De acordo com Peirce (2012), as pessoas pensam por meio de signos. Os signos mentais são de natureza mista, as partes-símbolos são chamadas conceitos. Se uma pessoa cria um novo símbolo, ela o faz por via de pensamentos que envolvem conceitos. Dessa forma, é possível que um novo símbolo se origine e se desenvolva a partir de símbolos preexistentes. Uma vez existente, o símbolo dissemina-se. Por meio do uso e da experiência, seu significado se amplia. Em suma, um símbolo é aplicável a tudo aquilo que possa concretizar a ideia relacionada com a palavra.

Um símbolo é um signo que perderia o caráter que o torna símbolo se não houvesse interpretante. "Tal é qualquer modulação de fala que significa o que significa apenas por se entender que tem aquela significação" (PEIRCE, 1975, p. 131). Peirce (2012) adverte, em síntese, que tudo o que está imediatamente 
presente à consciência de alguém é tudo aquilo que está na sua mente no instante presente - primeiridade (qualidade, possibilidade). Agir, reagir, interagir e fazer são modos marcantes concretos e materiais de dizer ao mundo; estas ações representam a secundidade (existência). A terceiridade (lei) aproxima o primeiro e o segundo em uma síntese intelectual, corresponde à camada de inteligibilidade, ou pensamento em signos, por meio da qual as pessoas representam e interpretam o mundo.

c) Modelagem

De acordo com Biembengut (2014),

\begin{abstract}
Modelagem é o processo envolvido na elaboração de modelo [...]. Trata-se de um processo de pesquisa. A essência deste processo emerge na mente de uma pessoa quando alguma dúvida genuína ou circunstância instigam-na a encontrar uma melhor forma para alcançar uma solução, descobrir um meio para compreender, solucionar, alterar, ou ainda, criar ou aprimorar algo (p. 21).
\end{abstract}

Assim, assume-se a modelagem ser "um processo dinâmico de busca de modelos adequados, que sirvam de protótipos de alguma entidade" (BASSANEZI, 2002, p. 45). É possível presumir que nas ciências os modelos desempenham papel essencial na elaboração do conhecimento. Apesar de uma teoria não se restringir a um modelo, ou somente a modelos se encadeando, visto que necessitam de outros elementos que as constituam, pode-se dizer que sem modelos, poderiam sequer existir (MOREIRA, 2014). Entende-se, também, que modelos são também fundamentais para o desenvolvimento cognitivo:

\footnotetext{
Aprender Ciências e Matemática é muito mais do que construir um ou outro modelo, ou incorporar cognitivamente um modelo pronto, como se fosse definitivo. É modelar permanentemente! A aprendizagem significativa implica uma interação cognitiva entre conhecimentos prévios e novos conhecimentos, [...]. A modelagem permeia tudo isso. Aprender e modelar estão intrinsecamente relacionados. Enquanto está modelando, o sujeito, o(a) aluno(a) no caso, está aprendendo e vice-versa (MOREIRA, 2014, p. 15-16).
} 
De acordo com Bassanezi (2002), a modelagem (matemática) faz uma ligação entre as representações e o mundo. $\mathrm{O}$ autor define como um processo dinâmico, utilizado para se obter e validar modelos (matemáticos). Ele considera uma forma de abstração e generalização com intuito de prever tendências. "A modelagem consiste, essencialmente, na arte de transformar situações da realidade em problemas matemáticos cujas soluções devem ser interpretadas na linguagem usual" (BASSANEZI, 2002, p. 24). Nessa perspectiva, o benefício da modelagem (matemática) é possibilitar, por meio de cálculos, validar o modelo, efetuar previsões sobre o comportamento do sistema e tentar controlá-lo (BASSANEZI, 2002). É que o processo permite uma aproximação da realidade sobre apresentações de um sistema ou parte dele.

Assim como Bassanezi (2002), Biembengut (2007) e Blum (2007), outros autores afirmam que o processo de elaboração de modelos se dá por meio de muitas interações. Para se iniciar um trabalho utilizando modelagem é necessário dispor de uma "situação-problema" que para sua solução não se disponha de dados suficientes para se utilizar de uma fórmula ou um caminho de solução. Assim, requer um levantamento de possíveis situações de estudo as quais devem ser, preferencialmente, abrangentes para que se possam proporcionar questionamentos em várias direções.

Começa-se a modelar a partir da escolha de um tema, assunto, ou situação-problema, passando, posteriormente a esta escolha, à etapa de coleta de dados. De acordo com Biembengut (2014), ao se interagir com os dados torna-se mais clara a situação, e é importante nesta etapa efetuar uma detalhada descrição. Após estas etapas iniciais busca-se descobrir a configuração das questões, examinar fatos e amostragens, com a intenção de subsidiar alicerces para uma generalização; analisar a natureza e a extensão do problema, formulando hipóteses; arrolar as soluções viáveis ou as possíveis maneiras de se chegar a elas; determinar a escolha da solução que parecer mais conveniente para a formulação do modelo.

Após a formulação do modelo matemático, passa-se então para a resolução do problema a partir do modelo, interpretação da solução e validação do modelo - avaliação. De acordo com Bassanezi (2002), Blum (2007) e Biemben- 
gut (2007), para utilização do modelo é preciso verificar em que nível este se aproxima da situação-problema apresentada. Assim, a interpretação do modelo pode ser por meio da análise das implicações da solução, derivada do modelo que está sendo investigado, para então verificar sua adequabilidade, retornando à situação-problema estudada, avaliando o quão significativa é a solução. Se o modelo não atender às necessidades que o geraram, retorna-se ao processo, mudam-se hipóteses, entre outras providências. Por este motivo, Blum (2007) considera a modelagem um processo cíclico.

Biembengut (2014) sintetiza o processo de modelagem em três fases: $:^{15}$

$1^{\circ}$ ) Percepção e Apreensão

Percepção consiste em receber, identificar e classificar informações provenientes do meio ou do próprio corpo. "A percepção implica na capacidade de captar eventos ou ideias, misturar, selecionar e relacionar com as que dispomos" (BIEMBENGUT, 2003, p. 6). A percepção é a primeira fonte de conhecimento necessária para que se possa fazer uma descrição do meio, uma decodificação e representação. Posteriormente a percepção tem relação com o pensamento, a resolução de problemas e os processos de decisão das pessoas. Trata-se de uma mediação necessária, mesmo que não suficiente de toda objetivação real.

$2^{\circ}$ ) Compreensão e Explicitação

A compreensão pode ser considerada a ligação entre a percepção e o conhecimento. Compreender significa expressar, mesmo que intuitivamente, uma sensação. "Uma vez tendo sido sensibilizada com o fato apresentado, a mente procura explicar, relacionar com algo já conhecido e deduzir os fenômenos que daí derivam" (BIEMBENGUT, 2003, p. 8). A autora afirma que as informações e os estímulos são percebidos e podem ser compreendidos pela mente, que procura explicar ou explicitar, delineando símbolos ou fragmentos de símbolos.

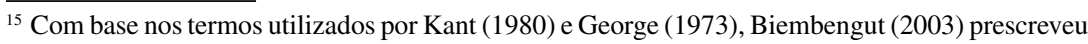
um método para o ensino de Ciências e Matemática denominado de "Modelagem na Educação - Modelação". 
As percepções ou informações recebidas são selecionadas pela mente, que, sobretudo, processa o que for interessante ou que está disponível para gerar ideias, compreensões e entendimentos.

$3^{\circ}$ ) Significação e Expressão

As percepções e/ou informações são compreendidas e explicadas em uma busca por traduzir ou representar estas percepções. Isto acontece com a utilização de símbolos e/ou modelos, afirma Biembengut (2003). Estas representações mentais, chamadas de símbolos e/ou modelos, podem ser internas ou externas. "As representações internas são aquelas que construímos no sistema cognitivo para a compreensão do meio em que vivemos, sendo uma forma de sobrevivência, e as externas as que se consegue expressar ou produzir externamente como pinturas, fotografias, objetos, etc." (BIEMBENGUT, 2003, p. 8-9).

\section{Articulações Possíveis - Tríade de Tensionamentos Teóricos}

Para facilitar o reconhecimento da articulação entre as teorias, será feita uma apresentação em três etapas, uma vez que as teorias apresentadas - aqui convergindo para novas expressões e considerações teóricas - coincidem no fato de se dividirem em passos em direção a um fim explicativo/elucidativo. Dessa forma articulou-se do seguinte modo:

I) Na teoria cognitiva, o primeiro estágio consiste no recebimento de informações e percepções por meio dos órgãos dos sentidos - interação. É a etapa em que os neurônios, em função de seus prolongamentos até os órgãos dos sentidos, percebem determinada informação. Pode-se dizer que corresponde à fase de primeiridade, de acordo com a semiótica, pois, nesta fase, considerada como primeira etapa, atua nos sentidos, no imediato, é algo imediatamente presente, uma qualidade ou possibilidade: um ícone. 
Biembengut (2014) define o primeiro estágio da modelagem em percepção e apreensão, equivalente à escolha do tema e familiarização com o assunto apresentado por Bassanezi (2002). Nesta etapa há o primeiro contato com a situação-problema, quando se percebe e apreende o que deve ser feito a partir de então.

II) No processo cognitivo, após a percepção pelos órgãos dos sentidos de determinadas sensações, inicia-se a fase de compreensão destas percepções por meio da comunicação entre os neurônios gerando uma alteração elétrica e química no sistema nervoso. É quando ocorre a memória operacional, em que as informações passam pelos neurônios, mas ainda sem modificá-los. Esta etapa pode ser comparada à secundidade de Peirce, estágio da conexão, da intermediação, da ação, que é a mediadora da intencionalidade - índice. Na modelagem, esta é a etapa de compreensão e explicitação, quando há a explicação do fenômeno em termos de formulação e resolução de modelo, é o elo entre a percepção e o conhecimento.

III) A terceira fase do sistema cognitivo é o conhecimento, quando a memória deixa de ser operacional e passa a ser de longa duração. Nesta etapa ocorre modificação no cérebro, uma reorganização estrutural do sistema nervoso, memória esta consolidada durante o período de sono. Neste estágio, quando há modificação dos neurônios, considera-se que ocorreu a aprendizagem. Para Peirce a terceira etapa corresponde à terceiridade, período de representação e comunicação, interpretação e representação do mundo por meio de signos - símbolos. Na modelagem, é a fase de significação e expressão, quando ocorre a validação e avaliação do modelo, para posterior comunicação. Ou seja, quando se chega a esta etapa, pode-se considerar que o modelo está pronto, que a percepção inicial gerou um conhecimento, ocorrendo então a aprendizagem.

No Quadro 1, a seguir, consta uma síntese comparativa entre: os processos de modelagem (matemática) propostos por Bassanezi (2002) e Biembengut (2014); as categorias da semiótica propostas por Peirce (2012); e os entendimen- 
tos em relação aos processos de cognição. Considerou-se pertinente o quadro a seguir para uma melhor visualização de como as teorias podem ser articuladas e categorizadas.

Quadro 1 - Síntese comparativa entre processos de modelagem, semiótica e cognitivos

\begin{tabular}{|l|l|l|l|}
\hline \multicolumn{2}{|c|}{ MODELAGEM } & SEMIÓTICA & \multicolumn{1}{c|}{ COGNIÇÃO } \\
\hline $\begin{array}{l}\text { Percepção } \\
\text { e Apreensão }\end{array}$ & $\begin{array}{l}\text { Reconhecimento } \\
\text { Familiarização. }\end{array}$ & Primeiridade & $\begin{array}{l}\text { Percepções do meio pelos } \\
\text { órgãos do sentido }\end{array}$ \\
\hline $\begin{array}{l}\text { Compreensão } \\
\text { e Explicitação }\end{array}$ & $\begin{array}{l}\text { Formulação do problema } \\
\text { Formulação do modelo. }\end{array}$ & Secundidade & $\begin{array}{l}\text { Formulação de modelos } \\
\text { mentais na memória de ope- } \\
\text { racional }\end{array}$ \\
\hline $\begin{array}{l}\text { Significação } \\
\text { e Expressão }\end{array}$ & $\begin{array}{l}\text { Resolução } \\
\text { Interpretação }\end{array}$ & Terceiridade & $\begin{array}{l}\text { Sinapses e consolidação da } \\
\text { memória de longa duração - } \\
\text { aprendizagem }\end{array}$ \\
\hline
\end{tabular}

Fonte: Os autores (2016).

Pelo exposto, as teorias mostram que as pessoas fazem uso de representações e se utilizam de modelos para adquirir conhecimento. Johnson-Laird (1990) afirma que os processos mentais se dão por meio de símbolos, ou seja, signos, e que a aprendizagem depende de associações.

\section{Considerações Finais}

Para a fortuna dos seres humanos, nem tudo que se percebe é compreendido. A maioria das percepções não chega a este segundo estágio, sendo excluído pela mente por ser irrelevante ou não merecer atenção prolongada. A compreensão é a etapa que une a percepção ao conhecimento. A partir da compreensão, algo $^{16}$ percebido adquire significado e, por consequência, pode vir a se tornar conhecimento. Cabe salientar, também, que nem tudo que é compreendido é significado, ou seja, torna-se, efetivamente, conhecimento. As informações da memória de curto prazo não necessariamente se tornam memórias de longa duração.

${ }^{16}$ Fenômeno, informação ou dado que configurem uma impressão. 
A mente humana seleciona, filtra e classifica as percepções e informações captadas, processando aquilo que interessa ou que está disponível para gerar ideias, compreensões e entendimentos, que são, por sua vez, singulares em cada pessoa. Depois de compreendida, uma informação adquire significados, de variadas complexidades, habilitando a pessoa para expressar e comunicar a outras o que sabe, pensa e entende daquilo que internalizou sobre o mundo que a cerca.

A partir daí há uma busca para representá-la ou traduzi-la; estas representações são feitas por meio de símbolos ou modelos. Tais representações mentais podem ser internas somente ou interno-externas. ${ }^{17}$ As representações internas são aquelas que a pessoa constrói na mente e não expressa, por diversas razões. E as interno-externas são as que a pessoa consegue expressar produzindo, por meio de modelos, desenhos, escrituras, esculturas, vocalizações e outras expressões corporais.

Quando uma compreensão passa a ser significativa para a mente, pode-se dizer que se transformou em conhecimento, ou seja, ocorreu a aprendizagem. Conforme Johnson-Laird (1990), as principais tarefas realizadas pela mente são: perceber o mundo; aprender, recordar e controlar ações; pensar e criar novas ideias; controlar a comunicação com outros; e criar a experiência dos sentimentos, das intenções e da autoconsciência. Johnson-Laird (1990) afirma que processos mentais são os vários números de percepções, ideias, crenças, hipóteses, pensamentos e recordações. Segundo o autor, um dos princípios da ciência cognitiva é que estas entidades são representações mentais ou símbolos de um ou outro tipo.

Neste universo, os fenômenos mentais dependem do cérebro, e a melhor maneira de explicá-los é por meio de símbolos. (JOHNSON-LAIRD, 1990). A quantidade de símbolos diferentes correspondentes a imagens, crenças e recordações, é potencialmente infinita; todavia a mente humana pode conter um número infinito de símbolos pre-existentes. Tal imensa variedade de símbolos

${ }^{17}$ Visto que não pode existir uma representação somente externa. 
mentais deve construir-se a partir de meios finitos, ou de símbolos primitivos. Dessa forma, segundo o autor, as pessoas pensam por meio de símbolos, por meio de signos, ou seja, por meio de modelos.

Com base nas ideias de Peirce, relacionando com as questões de aprendizagem, pode-se afirmar que um signo, que representa um objeto, gera um interpretante (aprendizagem), que pode gerar outro signo mais elaborado, que gera outro interpretante também mais elaborado, e assim sucessivamente. Considera-se, portanto, que a aprendizagem se efetue desta forma, quanto mais extensa e intensamente uma pessoa se envolva com um assunto/tema, mais se geram-se novos signos e consequentemente novos interpretantes. A aprendizagem efetiva-se por meio da percepção, que é o instrumento mediador entre as relações do ser humano e de seu entorno, em que os signos são utilizados como instrumentos para mediar a atividade mental. Sendo assim, a aprendizagem também ocorre por meio de signos.

Tomar a aprendizagem a partir dos signos e das criações possíveis distancia-se da ideia da aprendizagem como ato de representação, como efeito de uma mera adequação metodológica, como reflexo possível da movimentação de saberes e linguagens e a propõe como ato de inventividade, de liberdade e de criação imanente no agenciamento do trabalho escolar (BELLO; ZORDAN; MARQUES, 2015, p. 16).

Dessa forma, com base nas teorias descritas, pode-se afirmar que há uma relação entre os processos cognitivos, a semiótica e os procedimentos de modelagem. Com base nestes tensionamentos a aprendizagem escolar compreende essas etapas, tendo na modelagem um método que auxilia a consolidação da memória de longa duração, resultando na criação de signos - símbolos que se transformam em conhecimento.

A partir da tessitura de teorias articuladas neste artigo, é sugerida uma práxis educativa que visa ao aprendizado, fundada em sustentáculos teóricos da neurociência e da semiótica, e que pode ser um - dos vários - caminho(s) a ser(em) explorado(s) por professores em suas salas de aula e suas (im)possíveis (trans)formações. Sendo a ciência um campo de incertezas (PRIGOGINE, 1996), este artigo não buscou respostas conclusivas. Assim, à guisa de (in)conclusão 
lançam-se perguntas que visam ao convite a novas articulações. Intenta-se, portanto, verificar se as etapas da modelagem fazem parte da vida das pessoas em seus contextos profissionais e criativos, ou seja: Como se expressam as pessoas durante o processo criativo? Quais relações existirão entre os processos cognitivos e os de modelagem? Como tais processos podem impactar na educação básica e superior?

\section{Referências}

ALMEIDA, L. M. W.; DIAS, M. R. Um estudo sobre o uso da modelagem matemática como estratégia de ensino e aprendizagem. Bolema, Boletim de Educação Matemática (Impresso), Rio Claro: Unesp, ano 17, n. 22, p. 19-36, 2004.

ALMEIDA, L. M. W.; SILVA, K. A. P. Semiótica e as ações cognitivas dos alunos em atividades de modelagem matemática: um olhar sobre os modelos de inferência. In: Ciência \& Educação, vol. 18, n. 3, 2012.

ALMEIDA, L. M. W.; SILVA, K. A. P.; VERTUAN, R. E. Sobre a categorização dos signos na Semiótica Peirceana em atividade de Modelagem Matemática. Revista Electrónica de Investigación en Educación en Ciencias (En línea), v.v6, p.8-17, 2011.

BASSANEZI, R. C. Ensino-aprendizagem com modelagem matemática. São Paulo: Contexto, 2002.

BELLO, Samuel E. L.; ZORDAN, Paola; MARQUES, Diego. Signos e interpretação: entre aprendizagens e criações. In: Revista Cadernos de Educação, n. 52, 2015.

BIEMBENGUT, M. S. Mapeamento na pesquisa educacional. Rio de Janeiro: Editora Ciência Moderna, 2008.

. Modelagem \& Processo Cognitivo. In: Conferência Nacional de Modelagem e Educação Matemática, 3. CNMEM. Piracicaba, SP, 2003.

. Modelagem matemática \& implicações no ensino e aprendizagem de matemática.

3. ed. Blumenau: Edifurb, 2007.

. Modelagem matemática no Ensino Fundamental. Blumenau: Editora da Furb: 2014.

BLAKEMORE, Sarah-Jayne; FRITH, Uta. Cómo aprende el cerebro: las claves para la educación. Trad. Joan Soler. 1. ed. Barcelona: Ariel, 2007.

BLUM, W. et al. Modelling and Applications in Mathematics Education. Nova York: Springer, 2007. 
DAWKINS, R. O gene egoísta. São Paulo: Companhia das Letras, 2007.

GEORGE, F. Modelos de pensamentos. Trad. Mário Guerreiro. Petrópolis, RJ: Vozes, 1973.

GRANGER, Gilles Gaston. A razão. 2. ed. São Paulo: Difusão Européia do Livro, 1969.

GUERRA, Leonor. As contribuições da neurociência para a educação científica e tecnológica no contexto das realidades socioambientais: In: Congresso Internacional de Educação Científica e Tecnológica, 3. Santo Ângelo, 2015.

. Cérebro e aprendizagem: um diálogo entre neurociências e educação. In: Ciclo de palestras do Núcleo de Formação de Professores, 3. São Carlos, Ufscar: 2013. Disponível em: <https://www.youtube.com/watch?v=934wiekO-8g>. Acesso em: 9 dez. 2015. HUME, D. Investigação sobre o entendimento humano. Lisboa: Editora Setenta, 1985. JACOBY, S. L. S.; KOWALIK, J. S. Mathematical moderling with computers. New York: Prentice Hall, 1980.

JOHNSON-LAIRD, P. M. El ordenador y la mente: Introducción a la ciencia cognitiva. Trad. Alfonso Medina. Barcelona: Paidós, 1990.

KANT, I. Primeira introdução à crítica do juízo. Trad. Torres Filho, R. R. São Paulo: Abril Cultural, 1980.

MOREIRA, Marco Antônio. Modelos científicos, modelos mentais, modelagem computacional e modelagem matemática: aspectos epistemológicos e implicações para o ensino. In: Revista Brasileira de Ensino de $C \&$ T, v. 7, n. 2, 2014.

PEIRCE, Charles S. Semiótica. São Paulo: Perspectiva, 2012. . Semiótica e filosofia. São Paulo: Cultrix, 1975.

PRIGOGINE, I. O fim das certezas: tempo, caos e as leis da natureza. São Paulo: Editora Unesp, 1996.

SANTAELLA, Lucia. Matrizes da linguagem e pensamento. São Paulo: Iluminuras, 2009. . O que é Semiótica. São Paulo: Brasiliense, 2003.

SAUSSURE, Ferdinand. Curso de lingüística geral. Organização Charles Bally e Albert Sechehaye. Colaboração Albert Riedlinger. Tradução Antônio Cheline, José Paulo Paes e Izidoro Blikstein. São Paulo: Cultrix, 2006.

Recebido em: 17/7/2016

Aceito em: 4/11/2016 